\title{
VISIBLE SPECTRUM INCANDESCENT SELECTIVE EMITTER
}

\author{
I\&I Final Report \\ March 10, 2004 \\ AWARDEE \\ SONSIGHT INC. \\ 17609 Clinton Drive \\ Accokeek, MD 20607 \\ Phone: (301) 283-6250 \\ Email:dr_mcintosh@hotmail.com
}

\begin{abstract}
AUTHOR
Devon R. McIntosh, Principal Investigator
\end{abstract}

Award Number: DE-FG36-02G012066

Term: August 1, 2002 to January 31, 2004 


\section{Executive Summary}

The purpose of the work performed was to demonstrate the feasibility of a novel bi-layer selective emitter. Selective emitters are incandescent radiant bodies with emissivities that are substantially larger in a selected part of the radiation spectrum, thereby significantly shifting their radiated spectral distribution from that of a blackbody radiating at the same temperature. The major research objectives involved answering the following questions: (1) What maximum VIS/NIR radiant power and emissivity ratios can be attained at 2650 $\mathrm{K}$ ?

(2) What is the observed emitter body life and how does its performance vary with time?

(3) What are the design tradeoffs for a dual heating approach in which both an internally mounted heating coil and electrical resistance self-heating are used?

(4) What are the quantitative improvements to be had from utilizing a bi-layer emitter body with a low emissivity inner layer and a partially transmissive outer layer?

Two approaches to obtaining selective emissivity were investigated. The first was to utilize large optical scattering within an emitter material with a spectral optical absorption that is much greater within the visible spectrum that that within the NIR. With this approach, an optically thick emitter can radiate almost as if optically thin because essentially, scattering limits the distance below the surface from which significant amounts of internally generated radiation can emerge. The performance of thin emitters was also investigated (for optically thin emitters, spectral emissivity is proportional to spectral absorptivity). These emitters were fabricated from thin mono-layer emitter rods as well as from bi-layer rods with a thin emitter layer mounted on a substrate core. With an initially estimated energy efficiency of almost three times that of standard incandescent bulbs, a number of energy, economic and environmental benefits such as less energy use and cost, reduced $\mathrm{CO}_{2}$ emissions, and no mercury contamination was initially projected. 
The work performed provided answers to a number of important questions. The first is that, with the investigated approaches, the maximum sustained emitter efficiencies are about 1.5 times that of a standard incandescent bulb. This was seen to be the case for both thick and thin emitters, and for both mono-layer and bi-layer designs. While observed VIS/NIR ratios represent improvements over standard incandescent bulbs, it does not appear sufficient to overcome higher cost (i.e. up to five times that of the standard bulb) and ensure commercial success. Another result is that high temperatures (i.e. $2650 \mathrm{~K}$ ) are routinely attainable without platinum electrodes. This is significant for reducing material costs. A novel dual heating arrangement and insulated electrodes were used to attain these temperatures. Another observed characteristic of the emitter was significant grain growth soon after attaining operating temperatures. This is an undesirable characteristic that results in substantially less optical scattering and spectral selectivity, and which significantly limits emitter efficiencies to the values reported. Further work is required to address this problem. 


\section{PROJECT DESCRIPTION}

\section{Original Project Goals and Objectives}

The overall research goals were to: (1) develop a novel heating arrangement to attain and maintain high, stable incandescent temperatures, and (2) optically and physically optimize the composite ceramic oxide emitter such than when heated to high operating temperatures, it emits, within the IR, a much smaller portion of its total radiated power than that emitted by state-of-the-art incandescent bulbs.

The particular project objectives were to answer the following questions:

(1) What maximum VIS/NIR radiant power and emissivity ratios can be attained at 2650 $\mathrm{K}$ ?

(2) What electronic switching configuration is most advantageous for use with the ballast/heater coil?

(3) What are the actual observed lifetimes and electrode performance of molybdenum electrodes?

(4) What is the observed emitter body life and how does its performance vary with time?

(5) What are the design tradeoffs for an internally mounted heating coil that must be large enough to heat effectively yet be so mounted as to preclude physical contact with the emitter body?

(6) What are the optimum refractory oxide volume fractions for high temperature operation?

(7) How accurately can we measure the emitter body temperature, the spectral intensity emissivity distribution of which is highly nonlinear?

(8) What are the quantitative improvements to be had from utilizing a bi-layer emitter body with a low emissivity inner layer and a partially transmissive outer layer?

(9) What are the tradeoffs associated with various mounting approaches of the emitter within the glass bulb?

(10) What is the improved estimate of manufacturing costs? 


\section{Variance From Original Goals and Objectives}

The first research goal was achieved in that a novel heating arrangement to attain and maintain high, stable incandescent temperatures was demonstrated; however, the second research goal of attaining within the IR, at high emitter operating temperatures, a much smaller portion of total radiated power than that emitted by state-of-the-art incandescent bulbs was not met. As a result, several directly related objectives downstream of this goal were also not achieved. Namely, determining the electronic switching configuration most advantageous for use with the ballast/heater coil, determining the tradeoff associated with various mounting approaches of the emitter within the glass bulb, and obtaining an improved estimate of manufacturing costs were not achieved. Instead, much time was spent pursuing alternatives for obtaining improved emitter efficiencies. The alternatives investigated include the following:

1. Utilization of rare earth oxide powders as optically selective components for improving spectral selectivity.

2. Fabrication of thin mono-layer emitter rods for possible use as optically thin emitters to eliminate dependence on large optical scattering for improved emitter efficiency.

3. Fabrication of emitter bi-layer rods with an optically thin emitter layer mounted on a substrate core.

\section{Discussion of Work Performed}

Task 1: Determine Baseline Efficiency at 2650 K \& Optimize High Temp. Microstructure and Volume Fractions

Starting with the ceramic oxide (i.e. zirconia, ceria, and terbium and dysprosium oxides) and carbon powder compositions, baseline VIS/NIR radiant power and emissivity ratios 
at temperatures up to $2650 \mathrm{~K}$ were determined by fabricating emitter rods with refractory oxide and pore structure configurations projected to yield high VIS selectivity. The powders were mixed within a planetary ball lab mixer at medium speeds after which a sucrose solution binder and castor oil plasticizer were added. The rods were formed via a ram extruder using dies with exit holes in the sub millimeter size range. Subsequent sintering was performed at approximately $1600 \mathrm{C}$ within a molydisilicide furnace. Short ceramic tubes with a $1 \mathrm{~mm}$ wall thickness formed from the same powder composition were also extruded and subsequently sintered to form end tubes and attached to the emitter ends of the emitter rod and cemented on. Platinum wire electrodes were then attached to both end tubes via a zirconia-based cement. The low thermal conductivity of the end tubes helps to maintain electrode temperatures are maintained well below the melting point of platinum. A propane flame was used to initially heat the emitter and attain its turn-on temperature, after which a $10 \mathrm{mT}$ vacuum was applied (air operation is possible but vacuum operation is more stable) within a bell jar. The radiated intensity spectrum for $\lambda=.4-1.04 \mu \mathrm{m}$ was measured with an Ocean Optics S2000 fiber optic spectrometer (VIS spectrum wavelengths are $\lambda=.4-.7 \mu \mathrm{m}$ ).

While short wavelength selectivity was observed with the fabricated emitters, grain growth at high operating temperatures significantly degraded the spectral selectivity. Fig. 1 is a micrograph of the emitter surface after sintering, while Fig. 2 shows the surface of a similar emitter after operation at $2540 \mathrm{~K}$. The figures demonstrate a ten-fold grain growth at high temperatures. Fig. 3 compares the spectral intensity spectra of two similar emitters. The emitter operated for 1 hour at 2460K show significantly less selectivity than an emitter newly heated to $2472 \mathrm{~K}$. This is explained by the grain growth seen in Fig. 2. The majority of the optical scattering occurs at the grain-void boundary. Larger grain sizes imply less optical scattering. Since greater optical scattering allows greater selectivities, and high temperature operation significantly increases grain size, extended time spent at high temperatures degrades spectral selectivity. 


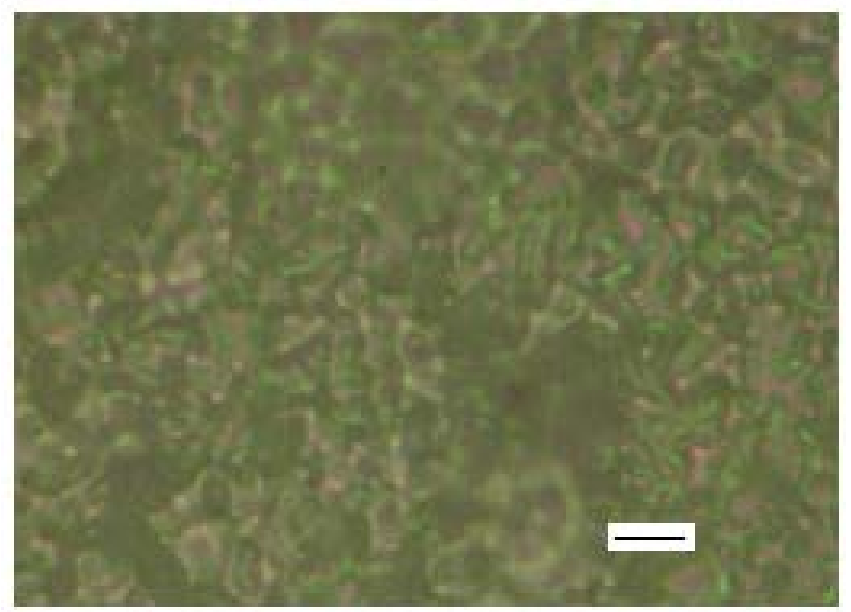

Fig. 1, Micrograph of unpolished emitter surface prior to high temperature operation showing grain sizes on the order of $1 \mu \mathrm{m}$ (the line length is $5 \mu \mathrm{m}$ ).

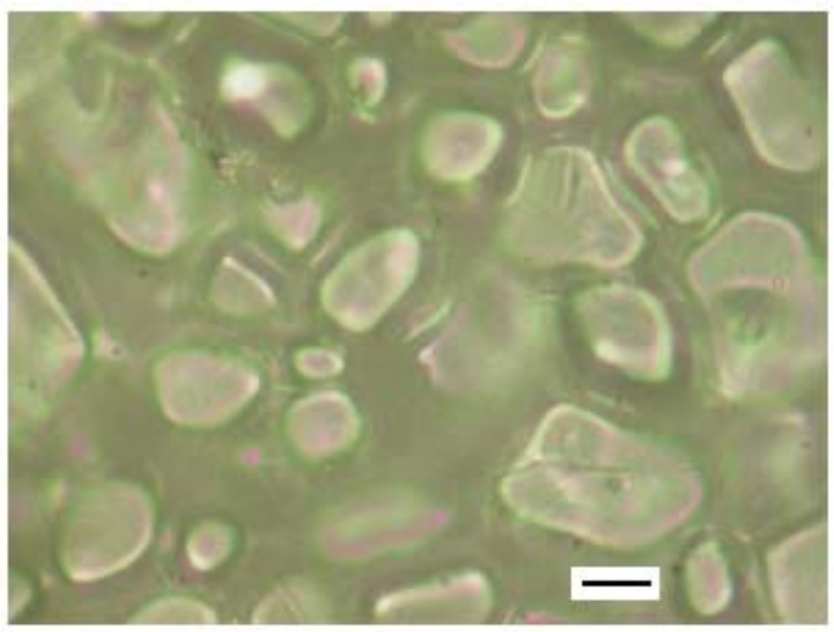

Fig. 2, Micrograph of unpolished emitter surface subsequent to high temperature operation showing grain sizes on the order of $10 \mu \mathrm{m}$ (the line length is $5 \mu \mathrm{m}$ ). 


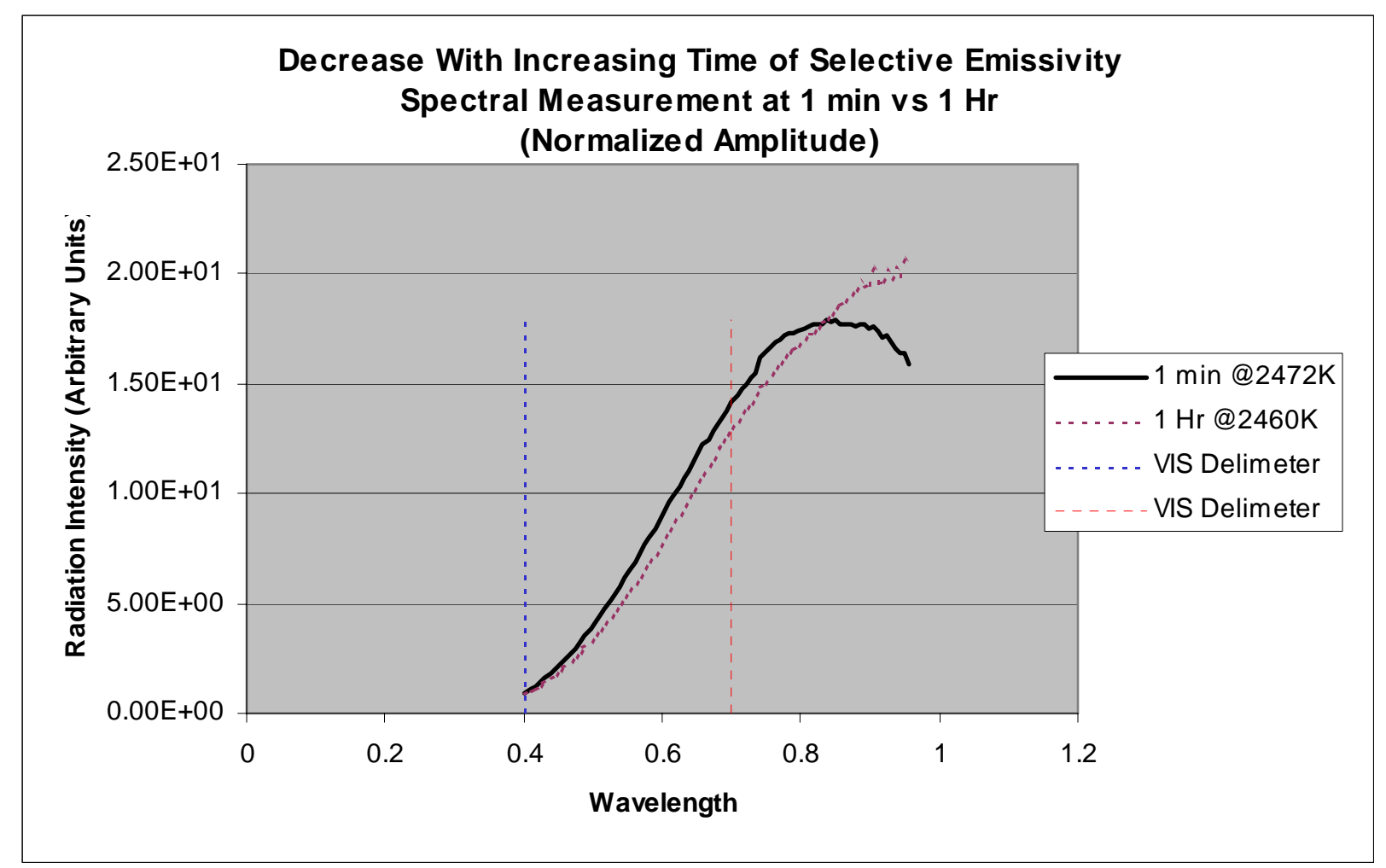

Fig. 3. Spectral distribution of emitters. Due to thermal induced changes in microstructure, the emitter operated for 1 hour at 2460K show significantly less selectivity than that operated for $\sim 1$ minute at $2472 \mathrm{~K}$.

The oxides of cerium, terbium and dysprosium were used to dope $13 \%$ yttria-stabilized zirconia and 3\% magnesia-stabilized zirconia to typical volume fractions of .02 to .2. Within this range, for a particular composition, the VIS/(VIS+NIR) ratios were not particularly sensitive to volume fraction, while for significantly larger volume fractions, stable operation was difficult. Average powder grain sizes were on the order of $1 \mu \mathrm{m}$ or less. Table 1 lists the obtained VIS/(VIS+NIR) ratio for the better samples. 
Table 1. Typical Measured VIS/(VIS+NIR) Ratios For Wavelengths of .4 $\mu \mathrm{m}-1.8$

$\mu \mathbf{m}$

\begin{tabular}{|c|c|c|c|c|}
\hline Dopant & $\begin{array}{c}\text { Measurement } \\
\text { Temperature } \\
\text { (K) }\end{array}$ & $\begin{array}{c}\text { Dopant } \\
\text { Volume } \\
\text { Fraction }\end{array}$ & $\begin{array}{c}\text { VIS/(VIS+NIR) } \\
\text { With Yttria } \\
\text { Stabilized } \\
\text { Zirconia Matrix }\end{array}$ & $\begin{array}{c}\text { VIS/(VIS+NIR) } \\
\text { With Magnesia } \\
\text { Stabilized } \\
\text { Zirconia Matrix }\end{array}$ \\
\hline Ceria & 2585 & .02 & .141 & .138 \\
\hline Calcia & 2548 & .05 & .120 & .123 \\
\hline $\begin{array}{l}\text { Terbium } \\
\text { Oxide }\end{array}$ & 2579 & .05 & & .091 \\
\hline $\begin{array}{l}\text { Dysprosium } \\
\text { Oxide }\end{array}$ & 2554 & .1 & & .103 \\
\hline
\end{tabular}

The corresponding solar VIS/(VIS+NIR) ratio is .48, and that of tungsten is .095. The best efficiency was obtained for ceria doping at 1.5 that of tungsten, while the worst was that for terbium oxide, which was slightly less than that of tungsten.

Task 2 and Task 3: Fabricate Baseline Emitter With Tungsten Coil Ballast/Heater and Characterize Emitter Stability, and Fabricate and Characterize Baseline Emitter With Molybdenum Electrodes

To establish the suitability of using molybdenum leads and using a heating coil instead of the propane torch to attain emitter turn-on temperature, emitters were mounted within external heating coils and placed within an evacuated (i.e. $10 \mathrm{mT}$ ) bell jar. First platinum and then molybdenum electrodes were used. As before, end tubes were used as thermal insulation between the electrodes and the ceramic oxide emitter. Two autotransformers were used to separately power the emitter and the heating coil. After energizing the coil to temperatures of up to $2310 \mathrm{~K}$ (1900 K, as determined by a Plank function fit to the measured spectral intensity distribution, was typically sufficient to attain emitter turn-on), 
power to the emitter was increased until it significantly conducted. The heating coil was turned off prior to making emitter spectral measurements.

Radiant heating was routinely used to achieve emitter turn-on. Fig. 4 shows one of the emitter mounting configurations used. In this particular example, two thin emitters are mounted vertically on molybdenum electrodes between two magnesium oxide tubes that serve to maintain fixed spacing between the emitters and the heating coil. A heating coil temperature of around $1900 \mathrm{~K}$ was typically sufficient to achieve emitter turn-on. A configuration with the emitter mounted concentrically along the axis of the heating coil was also used. The characterization of emitter stability was performed for tubular emitters and is described in that particular section below.

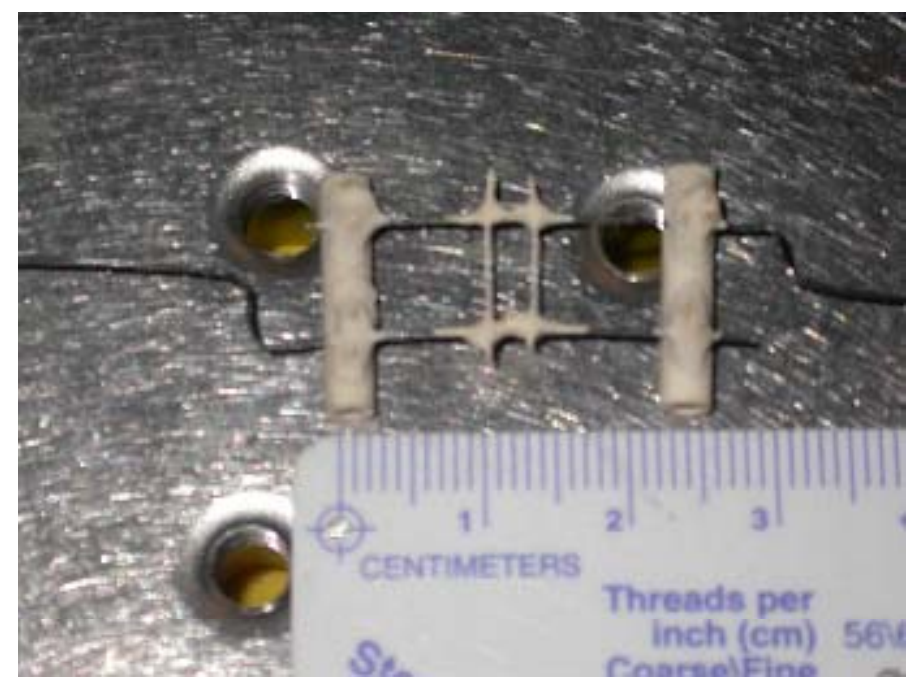

Fig. 4. Two thin emitters mounted on molybdenum electrodes between two magnesium oxide tubes (the tubes double as spacers for mounting within an external heating coil. 
Task 4, Task 5, and Task 6: Fabricate and Characterize Single-Layer Tubular Emitter, Fabricate and Characterize Bi-Layer Tubular Emitter, and Construct Emitter With Internally Mounted Ballast/Heater and Electronic Switching

Emitter bodies in the form of hollow tubes were extruded with the ram extruder and a tube die. Similar powder mixture compositions as that used for the rod emitters were used. And as before, similar short ceramic tubes formed from the same powder composition were extruded and sintered to form end tubes and attached to the emitter ends of the emitter tubes and cemented on. Molybdenum electrodes were then attached to the end tubes. To investigate the effect of tube wall thickness on emitter stability, the emitter was mounted within the heating coil and placed within the evacuated bell jar. Normally, the emitter is connected in series with resistive ballast, but for the purpose of this experiment, the ballast was removed, and except for a series connected ammeter (and a voltmeter connected across the electrodes), the emitter was connected directly across the autotransformer. After energizing the heating coil to a predetermined temperature, the emitter voltage was slowly increased. If normal stable operating voltage and current could not be attained, the heating coil temperature was increased and the process repeated until stable operation ensues. This process was repeated for several emitter diameters to obtain a better understanding of the effects of emitter dimensions and incident radiant intensity on emitter stability. Table 2 below summarizes the results of experiments performed to determine heating coil temperatures and lengths required to warm tubular emitters with internally mounted heating coils to the point where they electrically conduct and resistively self-heat. Table 3 shows the temperatures and coil lengths required to prevent thermal runaway. (Heating coil temperatures were determined by monitoring coil resistance via the supply current and voltage). 
Table 2. Minimum Coil Lengths And Temperatures Required For Heating Emitter To Turn-On Temperature (Coil lengths varied in $5 \mathrm{~mm}$ increments)

\begin{tabular}{|c|c|c|c|c|c|c|}
\hline \multirow{7}{*}{$\begin{array}{c}\text { Heating } \\
\text { Coil } \\
\text { Temperature }\end{array}$} & \multicolumn{6}{|c|}{ Tube OD = $3.2 \mathrm{~mm}$, Length = $20 \mathrm{~mm}$} \\
\hline & \multicolumn{3}{|c|}{ Tube ID $=2.5 \mathrm{~mm}$} & \multicolumn{3}{|c|}{ Tube ID = $1.5 \mathrm{~mm}$} \\
\hline & Min Coil & Min Coil & Min Coil & Min Coil & Min Coil & Min Coil \\
\hline & Length & Length & Length for & Length for & Length for & Length for \\
\hline & for Coil & for Coil & Coil OD = & Coil OD = & Coil OD = & Coil OD = \\
\hline & $\mathrm{OD}=.8$ & $\mathrm{OD}=1.1$ & $1.5 \mathrm{~mm}$ & $.8 \mathrm{~mm}$ & $1.1 \mathrm{~mm}$ & $1.5 \mathrm{~mm}$ \\
\hline & $\mathrm{mm}(\mathrm{mm})$ & $\mathrm{mm}(\mathrm{mm})$ & $(\mathrm{mm})$ & (mm) & (mm) & (mm) \\
\hline 2000 & * & * & 20 & * & * & ** \\
\hline 2100 & * & * & 20 & * & * & ** \\
\hline 2200 & * & 20 & 15 & * & * & ** \\
\hline 2300 & * & 20 & 15 & * & 20 & ** \\
\hline 2400 & * & 20 & 15 & * & 20 & ** \\
\hline 2500 & 20 & 15 & 10 & * & 20 & ** \\
\hline
\end{tabular}

* Max coil length of $20 \mathrm{~mm}$ unable to generate sufficient heat at this temperature.

** Coil OD too large to fit within emitter tube. 
Table 3. Minimum Coil Lengths And Temperatures Required To Prevent Thermal Runaway (coil lengths varied in $5 \mathrm{~mm}$ increments)

\begin{tabular}{|c|c|c|c|c|c|c|}
\hline \multirow{7}{*}{$\begin{array}{c}\text { Heating } \\
\text { Coil } \\
\text { Temperature } \\
\text { (K) }\end{array}$} & \multicolumn{6}{|c|}{ Tube OD = $3.2 \mathrm{~mm}$, Length $=20 \mathrm{~mm}$} \\
\hline & \multicolumn{3}{|c|}{ Tube ID = $2.5 \mathrm{~mm}$} & \multicolumn{3}{|c|}{ Tube ID $=1.5 \mathrm{~mm}$} \\
\hline & Min Coil & Min Coil & Min Coil & Min Coil & Min Coil & Min Coil \\
\hline & Length & Length & Length for & Length for & Length for & Length for \\
\hline & for Coil & for Coil & Coil OD = & Coil OD = & Coil OD = & Coil OD = \\
\hline & $\mathrm{OD}=.8$ & $\mathrm{OD}=1.1$ & $1.5 \mathrm{~mm}$ & $.8 \mathrm{~mm}$ & $1.1 \mathrm{~mm}$ & $1.5 \mathrm{~mm}$ \\
\hline & $\mathrm{mm}(\mathrm{mm})$ & $\mathrm{mm}(\mathrm{mm})$ & $(\mathrm{mm})$ & $(\mathrm{mm})$ & $(\mathrm{mm})$ & $(\mathrm{mm})$ \\
\hline 2000 & $*$ & $*$ & * & $*$ & * & ** \\
\hline 2100 & $*$ & * & $*$ & $*$ & $*$ & ** \\
\hline 2200 & $*$ & * & 20 & $*$ & * & $* *$ \\
\hline 2300 & * & * & 20 & * & $*$ & $* *$ \\
\hline 2400 & * & 20 & 15 & * & $*$ & ** \\
\hline 2500 & $*$ & 20 & 15 & $*$ & $*$ & $* *$ \\
\hline
\end{tabular}

* Max coil length of $20 \mathrm{~mm}$ unable to generate sufficient heat at this temperature.

** Coil OD too large to fit within emitter tube.

For the $2.5 \mathrm{~mm}$ ID tube, Tables 1 and 2 show the following:

1. All three coils can heat the emitter to its turn-on temperature, but only the larger two will provide effective ballast (i.e. prevent thermal runaway).

2. The lowest coil temperature for effective ballast is $2200 \mathrm{~K}$ with the $1.5 \mathrm{~mm}$ coil, and $2400 \mathrm{~K}$ with the $1.1 \mathrm{~mm}$ coil; the $.8 \mathrm{~mm}$ coil cannot provide effective ballast.

3. A coil shorter than the emitter tube length can be used only if sufficiently hot and wide. In this case, only the $1.5 \mathrm{~mm}$ coil at $2400 \mathrm{~K}$ and $2500 \mathrm{~K}$ provide effective ballast at less than the full $20 \mathrm{~mm}$ length.

For the $1.5 \mathrm{~mm}$ ID tube, Tables 1 and 2 show that effective ballast could not be obtained, and the lowest coil temperature for heating the emitter to its turn-on temperature is 2300 
K achieved with the $1.1 \mathrm{~mm}$ diameter full length coil (the $1.5 \mathrm{~mm}$ coil was too large to fit within the emitter tube).

The VIS/(VIS+NIR) ratios of bi-layer bodies having a low emissivity inner layer and spectrally selective outer layer were found to have similar values as those shown in Table 1. Fig. 5 shows two bi-layer die designs, die-a and die-b, used to extrude bi-layer emitter bodies. In both cases, the outer layer material is packed within the outer section of the die insert, and the inner layer material subsequently loaded within the inner section of the insert or simply within the body of the ram extruder. Application of pressure by the ram causes the outer paste to flow through the bottom insert standoff (Fig. 6) and be coextruded with the inner paste to form the bi-layer emitter body. The inner chamber of the die shown in Fig. 5a is made sufficiently large to accommodate a tube forming insert for extruding bi-layer tubes. The dimensions most critical to determining outer layer thickness and maintaining relatively stable cross section dimensions are the inner and outer chamber sizes shown in Fig. 5, and the bottom insert standoffs shown in Fig. 6. As shown in Fig. 5a and Fig. 5b, the outer chamber cavities are both $3 \mathrm{~mm}$ thick, but the diea inner chamber is $10 \mathrm{~mm}$ wide, while the die-b inner chamber is $5 \mathrm{~mm}$ wide. Fig. 6 show side views of the die inserts removed from the outer die bushing. The die-a and die-b bottom insert standoffs are $1.5 \mathrm{~mm}$ and $2.5 \mathrm{~mm}$ respectively. Both inserts were used with a range of die sizes to obtain bi-layer bodies with various inner and outer layer dimensions. Fig. 7 is an end view of a typical un-sintered (i.e. green body) rod emitter extruded with the die-a insert, having a $1.2 \mathrm{~mm}$ OD and a $.06 \mathrm{~mm}$ thick outer layer. The die-b insert yields approximately twice the outer layer thickness as that of the die-a insert. The outer layer of the green-body shown in Fig. 7 was formed with approximately $50 \%$ carbon black by volume, which vaporized during sintering. Sintering temperatures of up to $1650 \mathrm{~K}$ were maintained for up to three hours. 


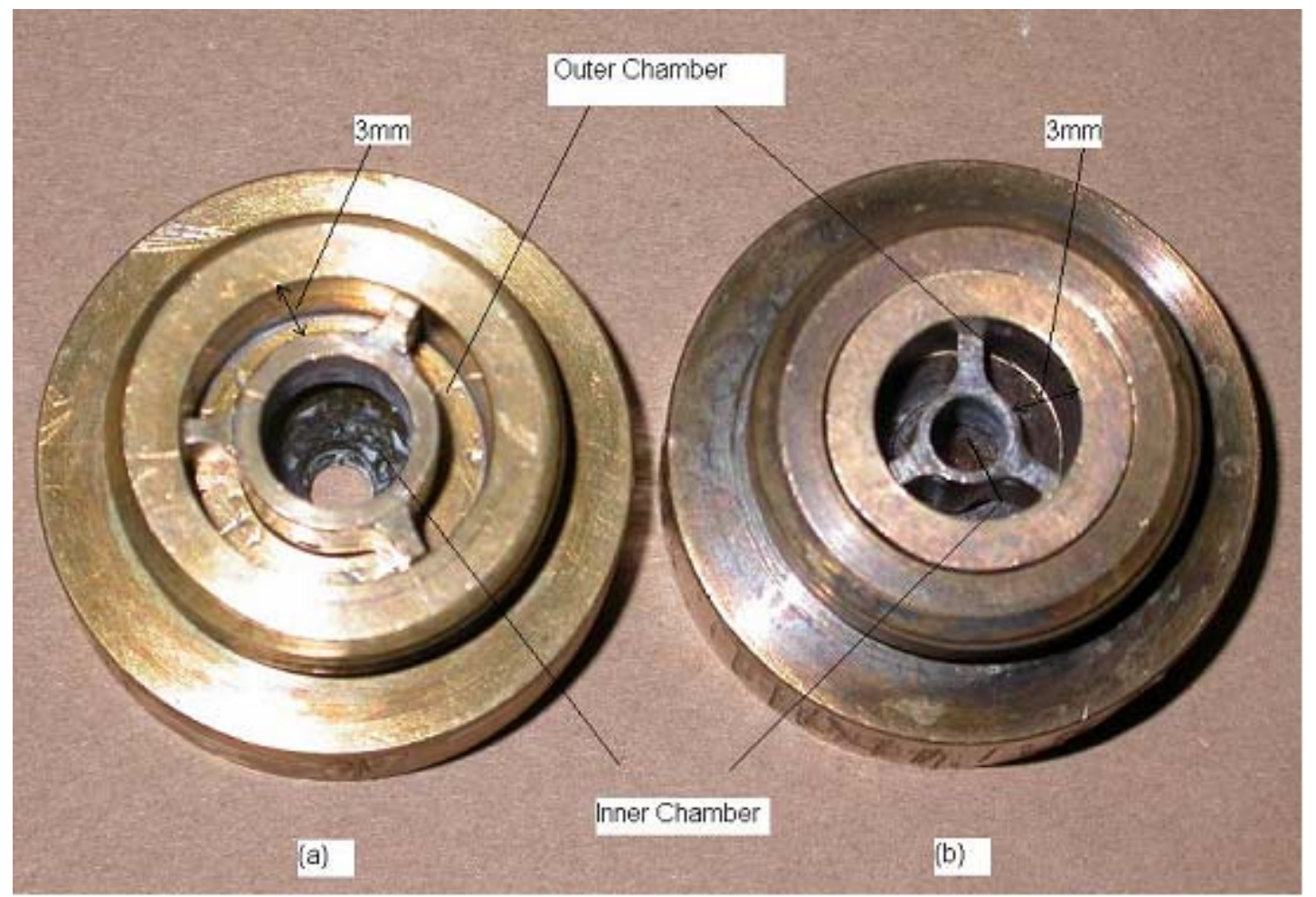

Fig. 5. Top view of two assembled bi-layer emitter rod dies. Outer and inner layer material are loaded within the outer and inner chambers respectively.

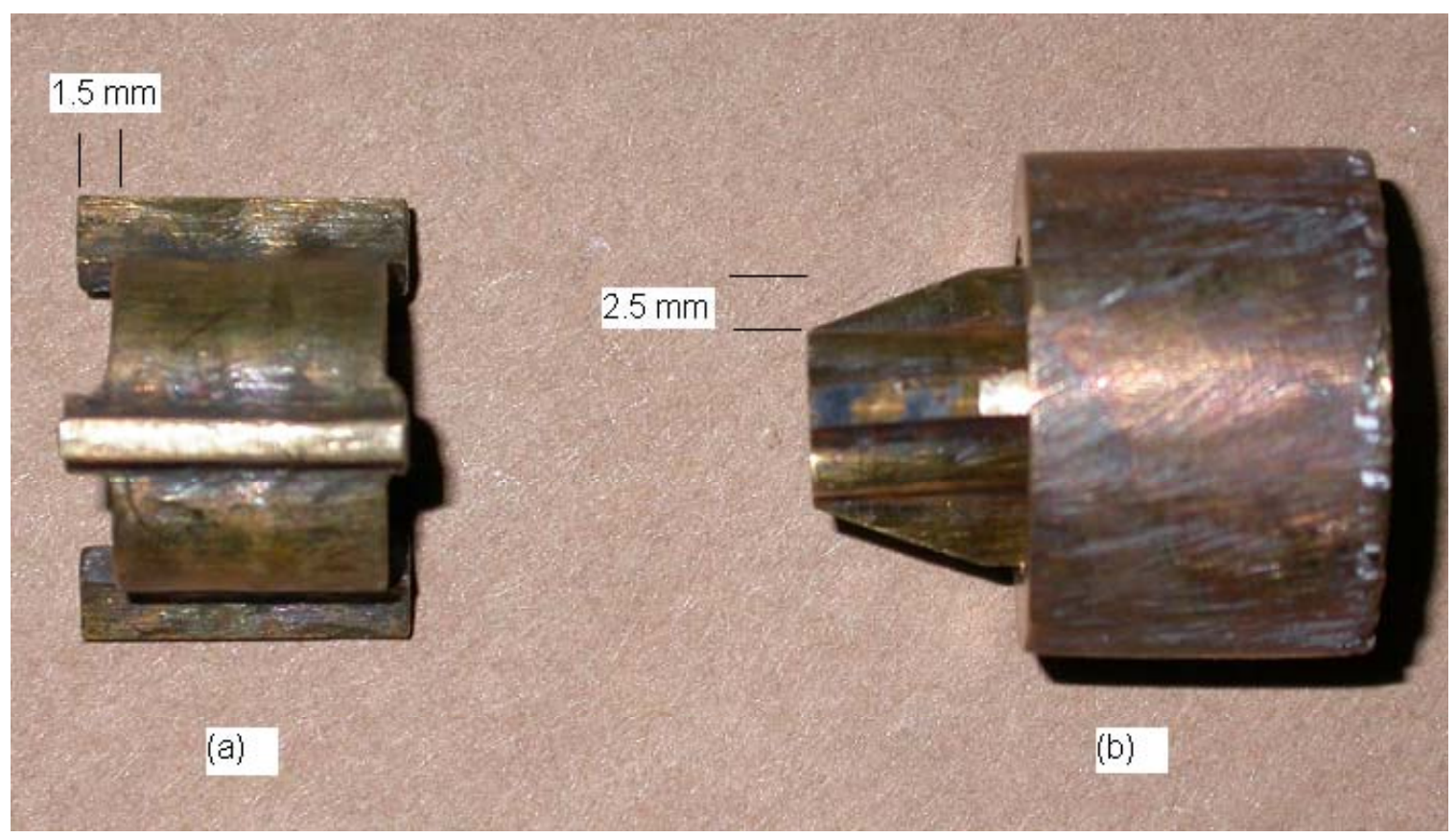

Fig. 6. Side view of the die inserts removed from the outer bushing. The bottom insert standoff of die-a is $1.5 \mathrm{~mm}$, and that of die-b is $2.5 \mathrm{~mm}$. 


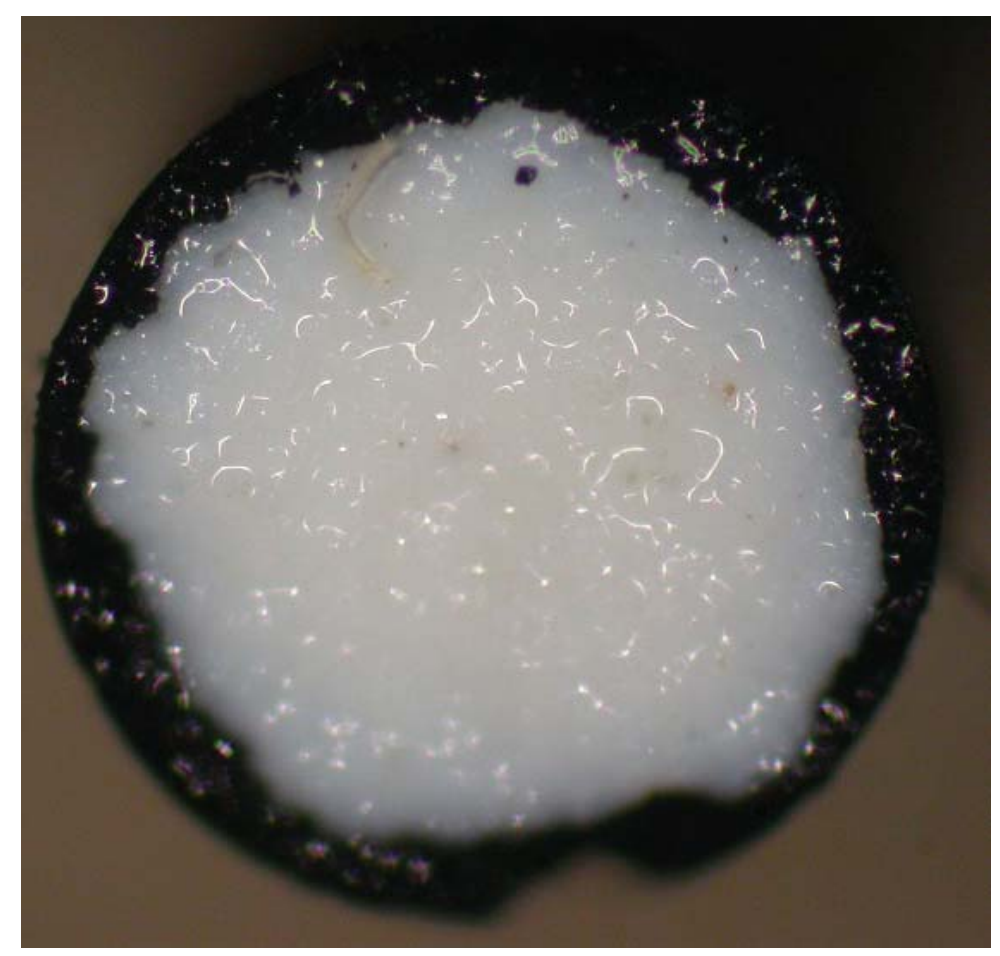

Fig. 7. Emitter rod of OD $1.2 \mathrm{~mm}$ and average outer layer thickness of .06 mm.

New Tasks: Fabricate Thin Mono-Layer Emitter Rods for Possible Use as Optically Thin Emitters, and Fabricate Emitter Bi-Layer Rods With an Optically Thin Emitter Layer Mounted on a Substrate Core.

Due to the grain growth at high temperatures and the resulting decrease in spectral selectivity, much work was directed towards developing optically thin emitters, which can achieve high spectral selectivity without large optical scattering. However, forming extruded bodies that are optically thin yet sufficiently strong to handle prior to and/or subsequent to sintering can be challenging. After some experimentation, an effective binder-plasticizer combination of approximately 30\% 2-ethylhexaonic acid and 70\% castor oil (by volume) were obtained. This, combined with extruder dies fabricated with exit diameters down to 100 microns and high sintering temperatures of around $1670 \mathrm{C}$ within a molydisilicide furnace permitted sintered rod diameters down to approximately 
70 microns. The green bodies are strong enough to be formed into a coil that remain strong and somewhat flexible after sintering. However, while rods of diameters down to 70 microns can be handled without undue breakage, emitter rods of at least twice this size seem to be required for stable operation. Unfortunately, spectral intensity measurements on these emitter rods demonstrated no notable improvements over that of the thicker emitters.

To ensure the emitter is optically thin with respect to optical scattering, nanometer grain sized zirconia powders ( $20 \mathrm{~nm})$ were used to fabricate thin emitter rods. In addition to mono-layer composite rods, bi-layer rods with inner layer thickness of $\sim 150$ microns and outer layer thickness of $\sim 30$ microns were formed. The emissivity of the inner layer was minimized by using magnesia-stabilized zirconia while the outer layer was formed from different mixtures of ceramic oxide powders. The goal was to form thin emitters (i.e. the outer layer) mounted on a low emissive substrate (i.e. the inner layer). However, due to its partial transparency to inner layer emissions, the outer layer emissivity could not be independently determined, and seemingly due to insufficient differences in emissivity between the inner and outer emitter layers, spectral intensity measurements showed negligible improvements in spectral selectivity.

\section{Conclusions and Recommendations for Future Work}

The work performed provided answers to a number of important questions. The first is that it is possible to routinely operate the emitter at high temperatures (i.e. $2650 \mathrm{~K}$ ) with insulating end tubes and molybdenum electrodes. Platinum need not be used, making the lamp significantly easier to commercialize.

A second conclusion is that it is possible to operate the emitter without resistive ballast, and use radiant heating instead. This is important because resistive ballast significantly decreases overall lamp efficiency. It should be possible to mount a heating coil within a 
hollow emitter body, and use the coil both to achieve the emitter turn-on temperature and to prevent thermal runaway.

Spectral intensity measurements show that, after high temperature operation, spectral output efficiencies of about 1.5 times that of a standard tungsten bulb are possible. Microscope analysis indicates this is due to significant grain growth resulting in substantially less optical scattering and spectral selectivity. Considering that the spectral efficiency of high temperature halogen bulbs is not far from this value of 1.5, greater spectral selectivity must be obtained before proceeding with commercialization.

Thin emitters of two types were investigated. The radiation spectra of mono-layer emitter rods of diameter 70 - 200 microns were measured and found to provide no significant increase in spectral selectivity. Subsequently, bi-layer rods with an outer emitter layer of approximately 30 microns and a lower emissive inner layer of approximately 150 microns were fabricated and radiated spectrum analyzed. No significant increase in spectral selectivity was observed. Utilizing estimations of the high temperature spectral absorptivities, rough calculations show that increased spectral selectivity may require an emitter thickness of less than 15 microns. This value is much too small to permit a free-standing emitter rod. However, a bi-layer rod with a 15 micron outer layer dimension may be possible with further work. Currently though, it is unclear if the spectral emissivity of the zirconia substrate at high temperatures is sufficiently low to preclude significant degradation of the overall emissivity.

The main technical obstacle to the original approach is finding a way to maintain considerable optical scattering for extended periods at high temperatures. Perhaps the best way forward is research into the effectiveness of various grain growth inhibitors applicable to the pertinent powder compositions. For instance, minute amounts of thoria has been effectively utilized within the construction of Welsbach gas lantern mantles to inhibit grain growth. Unfortunately, thoria is radioactive and its inclusion here, even in minute quantities would be undesirable. However, other grain growth inhibitors have been used in other mantle compositions as well, and perhaps it would be best to start with 
these. Once this hurdle is traversed, long term testing of the emitter and more accurate manufacturing cost projections can be undertaken.

\section{APPENDIX A}

\section{Final Task Schedule}

\begin{tabular}{|c|c|c|c|c|c|}
\hline Task \# & Task Title & \begin{tabular}{|c|} 
Original \\
Planned \\
Completion \\
Date
\end{tabular} & \begin{tabular}{|c|} 
Actual \\
Completion \\
Date
\end{tabular} & $\begin{array}{c}\text { Percent } \\
\text { Complete }\end{array}$ & Progress Notes \\
\hline Task 1 & $\begin{array}{l}\text { Determine Baseline Efficiencies at Target } \\
\text { Temp. \& Optimize High Temp. } \\
\text { Microstructure and Volume Fractions }\end{array}$ & $9 / 30 / 02$ & $12 / 30 / 03$ & 100 & $\begin{array}{l}\text { Due in large part to high } \\
\text { temperature grain growth, this } \\
\text { task was essentially extended to } \\
\text { include investigation of optically } \\
\text { thin emitters }\end{array}$ \\
\hline Task 2 & $\begin{array}{l}\text { Fabricate Baseline Emitter With Tungsten } \\
\text { Coil Component and Characterize Emitter } \\
\text { Stability }\end{array}$ & $11 / 30 / 02$ & $7 / 30 / 03$ & 100 & Completed \\
\hline Task 3 & $\begin{array}{l}\text { Fabricate Baseline Configuration With } \\
\text { Target Heat Supply Material and } \\
\text { Characterize }\end{array}$ & $12 / 31 / 02$ & $8 / 30 / 03$ & 100 & Completed \\
\hline Task 4 & $\begin{array}{l}\text { Fabricate Single-Layer Emitter Body and } \\
\text { Characterize Performance }\end{array}$ & 3/31/03 & $9 / 30 / 03$ & 100 & Completed \\
\hline Task 5 & $\begin{array}{l}\text { Fabricate Double-Layer Emitter Body and } \\
\text { Characterize Performance }\end{array}$ & $5 / 31 / 03$ & $11 / 30 / 03$ & 100 & Completed \\
\hline Task 6 & $\begin{array}{l}\text { Construct Emitter With Electrical and } \\
\text { Internally Mounted Components. }\end{array}$ & 8/31/03 & $10 / 30 / 03$ & 60 & $\begin{array}{l}\text { Due to low emitter performance } \\
\text { in its current form and the time } \\
\text { spent on Task 1, electronic } \\
\text { switching was not pursued }\end{array}$ \\
\hline Task 7 & $\begin{array}{l}\text { Mount Emitter Within Bulb and Fine-tune } \\
\text { Enclosed Performance }\end{array}$ & 11/30/03 & Not Done & 0 & $\begin{array}{l}\text { Due to low emitter performance } \\
\text { in its current form and the time } \\
\text { spent on Task 1, this task was not } \\
\text { undertaken. }\end{array}$ \\
\hline Task 8 & Project Management and Reporting & $12 / 31 / 03$ & $3 / 5 / 03$ & 100 & \\
\hline
\end{tabular}




\section{APPENDIX B}

\section{Final Cost Schedule}

Project Period: $8 / 1 / 02$ to $1 / 31 / 04$

\begin{tabular}{|c|c|c|c|}
\hline Task \# & Task Title & \begin{tabular}{|c|} 
Approved \\
Budget
\end{tabular} & Final Project Expenditures \\
\hline Task 1 & \begin{tabular}{|l|} 
Determine Baseline Efficiencies at \\
Target Temp. \& Optimize High Temp. \\
Microstructure and Volume Fractions
\end{tabular} & 20,000 & 59,800 \\
\hline Task 2 & $\begin{array}{l}\text { Fabricate Baseline Emitter With } \\
\text { Tungsten Coil Component and } \\
\text { Characterize Emitter Stability }\end{array}$ & 30,000 & 32,500 \\
\hline Task 3 & $\begin{array}{l}\text { Fabricate Baseline Configuration With } \\
\text { Target Heat Supply Material and } \\
\text { Characterize }\end{array}$ & 20,000 & 21,200 \\
\hline Task 4 & $\begin{array}{l}\text { Fabricate Single-Layer Emitter Body } \\
\text { and Characterize Performance }\end{array}$ & 25,000 & 23,900 \\
\hline Task 5 & $\begin{array}{l}\text { Fabricate Double-Layer Emitter Body } \\
\text { and Characterize Performance }\end{array}$ & 25,000 & 27,900 \\
\hline Task 6 & $\begin{array}{l}\text { Construct Emitter With Electrical and } \\
\text { Internally Mounted Components. }\end{array}$ & 50,000 & 28,500 \\
\hline Task 7 & $\begin{array}{l}\text { Mount Emitter Within Bulb and Fine- } \\
\text { tune Enclosed Performance }\end{array}$ & 25,000 & 0 \\
\hline Task 8 & Project Management and Reporting & 10,000 & 11,200 \\
\hline & Total & 205,000 & 205,000 \\
\hline & DOE Share & 200,000 & 200,000 \\
\hline & Cost Share & 5,000 & 5,000 \\
\hline
\end{tabular}




\section{APPENDIX C}

Final Cost Share Contributions

Final Cost Share Contributions

\begin{tabular}{|c|c|c|c|c|}
\hline \multirow[t]{2}{*}{ Funding Source } & \multicolumn{2}{|c|}{$\begin{array}{c}\text { Approved Cost } \\
\text { Share }\end{array}$} & \multicolumn{2}{|c|}{ Final Contributions } \\
\hline & Cash & In-Kind & Cash & In-Kind \\
\hline Sonsight Inc. & & 5,000 & & 5,000 \\
\hline & & & & \\
\hline & & & & \\
\hline & & & & \\
\hline Total & & 5,000 & & 5,000 \\
\hline Cumulative & ost Shal & Contribut & & 5,000 \\
\hline
\end{tabular}




\section{Energy Savings Metrics}

\section{One Unit of Proposed Technology:}

The energy consumption for the proposed unit (i.e. the selective emitter) in Btu/yr/unit is $3.4 \times \mathbf{1 0}^{5}$ Btu. The stated energy consumption is based on $67 \mathrm{~W}$ being expended by the emitter to produce 1580 lumens (which is that produced by a standard $100 \mathrm{~W}$ incandescent lightbulb) for an average of four hours per day for a year.

\section{One Unit of Current Technology:}

The energy consumption for the comparable competing (i.e. a typical halogen bulb) unit in Btu/yr/unit is $3.7 \times \mathbf{1 0}^{\mathbf{5}} \mathbf{B t u}$. This is based on $74 \mathrm{~W}$ being expended by a halogen bulb to produce 1580 lumens (which is that produced by a standard $100 \mathrm{~W}$ incandescent lightbulb) for an average of four hours per day for a year. 
Energy Savings Metrics

\begin{tabular}{|c|c|c|c|c|c|}
\hline & A & B & $\mathrm{C}=\mathrm{A}-\mathrm{B}$ & D & $E=C x D$ \\
\hline $\begin{array}{c}\text { Type of Energy } \\
\text { Used }\end{array}$ & $\begin{array}{c}\text { Current } \\
\text { Technology } \\
\text { (Btu / yr / } \\
\text { unit) }\end{array}$ & $\begin{array}{c}\text { Proposed } \\
\text { Technology } \\
\text { (Btu / yr / } \\
\text { unit) }\end{array}$ & $\begin{array}{c}\text { Energy } \\
\text { Savings } \\
\text { (Btu / yr / } \\
\text { unit) }\end{array}$ & $\begin{array}{c}\text { Estimated } \\
\text { Number of } \\
\text { Units in U.S. } \\
\text { by } 2010 \\
\text { (units) }\end{array}$ & $\begin{array}{c}\text { Energy } \\
\text { Savings by } \\
2010 \\
\text { (Btu / yr) }\end{array}$ \\
\hline Oil / Gasoline & & & & & \\
\hline Natural Gas & & & & & \\
\hline Coal & & & & & \\
\hline $\begin{array}{c}\text { Electricity (@ } \\
\text { 10,500 Btu / kWh) }\end{array}$ & 3.7 & 3.4 & .3 & N/A & N/A \\
\hline $\begin{array}{c}\text { Other Energy } 1 \\
\text { (Explain) }\end{array}$ & & & & & \\
\hline $\begin{array}{c}\text { Other Energy } 2 \\
\text { (Explain) }\end{array}$ & & & & & \\
\hline $\begin{array}{c}\text { Other Energy ...n } \\
\text { (Explain) }\end{array}$ & & & & & \\
\hline Total Per Unit & 3.7 & 3.4 & .3 & N/A & N/A \\
\hline
\end{tabular}

